\title{
Editorial of the Special Historical Issue
}

\author{
Stephen O. Dean
}

Published online: 26 March 2011

(C) Springer Science+Business Media, LLC 2011

This Special Historical Issue contains two papers of historical interest relating to the evolution of the US fusion program in the 1960s. The first, the 1966 AEC Policy and Action Paper on Controlled Thermonuclear Research, was prepared in response to a request from the US congressional (House-Senate) Joint Committee on Atomic Energy and the US House of Representatives Appropriations Committee. The second describes the history of a fusion concept unique to the US program, the Astron. It was first proposed in 1956, began construction in 1958, and ended in 1973.

The 1966 policy paper was prepared within the Controlled Thermonuclear Research (CTR) Branch of the AEC's Division of Research by Amasa S. Bishop and Stephen O. Dean, assisted by Richard F. Post of the Lawrence Livermore National Laboratory (then Lawrence Radiation Laboratory). The AEC was the original predecessor agency of the current US Department of Energy (DOE); its Research Division was the original predecessor of the current DOE Office of Science; and its CTR Branch was the original predecessor of the current DOE Office of Fusion Energy Sciences (OFES). Bishop was the first head of the US fusion program (1953-1956) and wrote the classic early history of fusion in the book Project Sherwood (Addison-Wesley Publishing Company 1958). He worked at the Princeton Plasma Physics Laboratory in the early 1960s, returning to once more head the US fusion program at AEC (1965-1970). He was a recipient of Fusion Power Associates Distinguished Career Award in 1992 and passed away in 1997. Dick Post is a pioneer of the US fusion program, dating back to the mid 1950s. He was the

S. O. Dean $(\varangle)$

Fusion Power Associates, Gaithersburg, MD 20879, USA

e-mail: fusionpwrassoc@aol.com recipient of Fusion Power Associates first Distinguished Career Awards in 1987 and is still active in research. Dean was a member of the AEC CTR Branch (1962-1969) and again 1972-1979, after a 3-year stint at the US Naval Research Laboratory doing experimental research on laserproduced plasmas. He has been President of Fusion Power Associates since 1979.

The Policy Paper was transmitted to Congress on July 11, 1966 by then AEC chairman Glenn Seaborg. A copy of the transmittal letter is contained in the paper. The transmittal letter states that the AEC's General Advisory Committee (GAC) and the President's Science Advisory Committee (now called PCAST), have reviewed the report and endorse "the importance of the program and the need for an intensified effort." The report also includes, as appendices, a 1962 review of the CTR program by the AEC's GAC and a review of the report by a special committee set up by the AEC in late 1965.

The report concludes, "By any standard whatsoever, controlled thermonuclear research must be counted as one of the most challenging and potentially important efforts in the history of mankind." It notes that "there are also compelling interests of a more basic nature for studying the behavior of plasmas" since "its bearing on other fields of knowledge and on the future activities of mankind may well be profound."

The central policy statement in the report reads as follows:

"The AEC program will continue to be motivated by interest in eventually achieving controlled thermonuclear power. It is recognized, however, that there are many benefits which will accrue from an investigation of this vast and largely-unexplored field. As a result, the effort will emphasize not only a detailed understanding of the physics of high temperature plasmas and the means for confining 
and heating them, but also studies of a basic nature in the broader aspects of the science and technology of plasmas."

As a result of the report, the AEC CTR Branch set up a CTR Standing Committee with planned Ad Hoc Working Panels. The charter for this committee is provided as Appendix 4 of the paper. This committee is the direct antecedent of the current DOE Fusion Energy Sciences Advisory Committee (FESAC).

The Astron paper was prepared by Elishiva Coleman based on a study she did of the history of the project when she was a student at Princeton University in 2004. It is unique in that it treats not only the technical ups and downs of the 17-year life of the project, but also the important role that personalities and politics played in its evolution. Indeed, Astron was the first project reviewed by an Ad Hoc Panel under the charter of the CTR Standing Committee established by the AEC policy paper.

The Astron sought to achieve a unique magnetic confinement geometry in which the external vessel was openended (cylindrical), yet the fusion plasma would experience a closed (toroidal) magnetic confining force. This was to be done by injecting a current of electrons (later protons were considered) from an accelerator into a vessel, having a solenoidal magnetic field produced by external magnets, at sufficient current to reverse the direction of the applied solenoidal field.

The Astron was also unique in that it was conceived and advocated by one of the most colorful characters in the history of fusion research, Nicholas Christofilos. As the author correctly notes, "Christofilos' unusual personality and proclivities ensured throughout that Astron's story would be distinctive."

Astron began operation in 1963 and was under almost continuous review and scrutiny within the fusion scientific and managerial community from day one. Early on, it reached only $6 \%$ of field reversal. At the time of Christofilos sudden death on September 241972 it had reached only $15 \%$. After his death, a team of scientists under the direction of Dick Briggs succeeded in raising that to $50 \%$, at which time (June 1973) the AEC terminated the effort. The story, as told by Ms. Eleshiva, is both entertaining and instructive. 